\title{
POTENSI SIMPANAN KARBON DI ATAS PERMUKAAN TANAH TEGAKAN Acacia nilotica L. (Willd) ex. Del. DI TAMAN NASIONAL BALURAN, JAWA TIMUR
}

\author{
Above ground carbon storage potential of stand of Acacia nilotica L. (Willd) ex. Del. in \\ Baluran National Park, East Java
}

\author{
Istomo $^{\mathrm{a}}$, Nur Eliya Farida ${ }^{\mathrm{b}}$ \\ ${ }^{a}$ Departemen Silvikultur, Fakultas Kehutanan, Institut Pertanian Bogor, Darmaga, Bogor 16680 - \\ istomo19@gmail.com. \\ ${ }^{b}$ Alumnus Fakultas Kehutanan IPB
}

\begin{abstract}
Acacia nilotica is an invasive species which is difficult to eradicate up to present. A. nilotica is a fast growing species of savanna tree, and therefore is supposed probably to have relatively high biomass and carbon content. The objective of this research was to develop allometric equation of biomass and estimating the carbon storage potential in A. nilotica stand in Baluran National Park. This research used destructive method on 9 sample trees to construct allometric equation. For measuring biomass potency, vegetation analysis was conducted using 3 plots, measuring $100 \mathrm{~m} \times 100 \mathrm{~m}$ each on the basis of A nilotica stand density categorization (high, medium, and low). For obtaining data of carbon potency, biomass value was multiplied with 0,47. Research results show that the selected allometric equation for tree total is $W=0,34 D^{1,97}$ with $R^{2}$ of 98,4 . Average biomass potency was as large as 25 tons/ha. Average carbon potency was 11,92 ton/ha. Management of A. niloticain Baluran National Park, in moderate and low density stand can be in the form of clear cutting, whereas high density stand can be maintained for carbon sequestration and utilization by the people community for supplying seeds, livestock feeds, firewood or charcoal briquette.
\end{abstract}

Keywords: Acacia nilotica, biomass, carbon stock, destructive sampling

(Diterima: 03-02-2017; Disetujui: 24-04-2017

\section{Pendahuluan}

Kajian biomassa merupakan langkah awal dari penelitian produktivitas yang sangat penting dipelajari untuk mengetahui siklus hara dan aliran energi dari suatu ekosistem hutan. Secara umum, kajian biomassa dibagi menjadi dua bagian, yaitu biomassa di atas tanah (above-ground biomass) dan biomassa di bawah permukaan tanah (below-ground biomass). Biomassa hutan memiliki kandungan karbon yang cukup potensial. Hampir 50\% dari biomassa vegetasi hutan tersusun atas unsur karbon (Brown, 1997). Unsur tersebut dapat dilepas ke atmosfir dalam bentuk karbon dioksida $\left(\mathrm{CO}_{2}\right)$ apabila hutan dibakar, sehingga jumlahnya bisa meningkat secara drastis di atmosfir dan menjadi masalah lingkungan global. Oleh karena itu, pengukuran terhadap biomassa sangat dibutuhkan untuk mengetahui berapa besar jumlah karbon yang tersimpan di dalam hutan (Tresnawan dan Rosalina, 2002).

Biomassa merupakan massa dari bagian vegetasi yang masih hidup yaitu batang, cabang, dan tajuk pohon, tumbuhan bawah atau gulma, dan tanaman semusim (Smith et al., 2004). Menurut Jenkins et al., (2003), biomassa dapat digunakan sebagai dasar dalam perhitungan kegiatan pengelolaan hutan, karena hutan dapat dianggap sebagai sumber dan sink dari karbon. Pendugaan biomassa hutan sangat berguna untuk menilai struktur dan kondisi hutan serta produktivitas hutan (Navar, 2009). Biomassa dibedakan ke dalam dua kategori yaitu biomassa di atas permukaan tanah (above-ground biomass) dan biomassa tumbuhan di bawah permukaan tanah (below-ground biomass).

Karbon merupakan suatu unsur yang diserap dari atmosfer melalui proses fotosintesis dan disimpan dalam bentuk biomassa. Tingkat penyerapan karbon di hutan dipengaruhi oleh berbagai faktor, antaralain iklim, topografi, karakteristik lahan, umur dan kerapatan vegetasi, komposisi jenis serta kualitas tempat tumbuh. Tempat penyimpanan utama karbon adalah terdapat dalam biomassanya (termasuk bagian atas yang meliputi batang, cabang, ranting, daun, bunga, dan buah serta bagian bawah yang meliputi akar), bahan organik mati, tanah dan yang tersimpan dalam produk kayu yang nantinya dapat diemisikan untuk produk jangka panjang (Widyasari, 2010).

Informasi yang akurat mengenai karbon hutan yang tersimpan dalam biomassa sangat diperlukan untuk menggambarkan kondisi ekosistem hutan dalam rangka pengelolaan sumberdaya hutan yang lestari sehingga menguntungkan secara ekonomi dan ekologi. Informasi ini juga sangat penting sebagai komponen dasar dalam perhitungan dan pemantauan karbon nasional yang merupakan input utama untuk mengembangkan strategi penurunan emisi Gas Rumah Kaca (GRK), terutama $\mathrm{CO}_{2}$ dari sektor lahan. Oleh karena itu, besar biomassa yang keluar dari hutan harus diimbangi dengan penambahan biomassa dalam hutan. 
Salah satu ekosistem hutan yang kaya akan keanekaragaman hayati, baik flora maupun fauna serta alamnya yang indah adalah Taman Nasional Baluran. Taman Nasional Baluran terbentang dari pantai sampai pegunungan dengan berbagai macam ekosistem. Savana merupakan tipe vegetasi yang dijumpai hampir di seluruh bagian kawasan Taman Nasional Baluran. Namun, saat ini savana tersebut sebagian besar telah terinvasi oleh spesies akasia berduri (Acacia nilotica L. (Willd) ex. Del.). A. nilotica termasuk ke dalam famili leguminoseae, sub famili mimosaidae yang diperkirakan berasal dari India, Pakistan, dan juga banyak ditemukan di Afrika. Spesies A. nilotica yang diintroduksi ke Indonesia merupakan sub spesies indica (Brenan, 1983). Introduksi tumbuhan ini ke Taman Nasional Baluran pada tahun 1969 bertujuan sebagai sekat bakar untuk menghindari menjalarnya api dari savana ke kawasan hutan jati (BTNB, 1999).

Menurut BTNB (2013), Taman Nasional Baluran ditetapkan sebagai taman nasional berdasarkan pengumuman Menteri Pertanian pada tanggal 6 Maret 1980. Berdasarkan SK Menteri Kehutanan Nomor: 279/Kpts-VI/1997 tanggal 23 Mei 1997 luas Taman Nasional Baluran adalah 25,000 ha, sedangkan berdasarkan SK. Dirjen PKA Nomor : 187/KptsDJV/1999 tanggal 13 Desember 1999, zonasi Taman Nasional Baluran terdiri dari zona inti seluas $\pm 12,000$ ha, zona rimba seluas 5637 ha (perairan 1063 ha, daratan $4574 \mathrm{ha}$ ), zona pemanfaatan intensif seluas 800 ha, zona pemanfaatan khusus seluas 5780 ha, dan zona rehabilitasi seluas 783 ha.

Taman Nasional Baluran memiliki beberapa tipe ekosistem antara lain meliputi hutan pantai, hutan bakau/mangrove, hutan savana (padang rumput alami), hutan selalu hijau (evergreen), hutan musim dataran rendah, dan hutan pegunungan. Kawasan ini memiliki jenis-jenis flora sekitar 475 spesies dengan 100 famili. Jenis tumbuhan tersebut antara lain 144 jenis pohon, 76 spesies tumbuhan perdu, 59 spesies rumput, 135 spesies herba, 42 spesies liana, 5 spesies anggrek, 13 spesies paku, dan 2 spesies parasit/epifit.

A. nilotica juga salah satu tumbuhan yang mampu menyerap dan menyimpan karbon, kemampuannya dalam menyerap dan menyimpan karbon akan menurun karena adanya pemusnahan A. nilotica sebagai spesies invasif yang mengganggu ekosistem savana. Penelitian biomassa di atas permukaan tanah untuk savana telah dilakukan oleh De Salis et al. (2006) di Brazil. Sedangkan penelitian model-model alometrik untuk jenis Acacia telah dilakukan oleh Rahmat (2007) untuk jenis A. crassicarpa, Heriyanto \& Siregar (2007), Wicaksono (2004) untuk jenis $A$. mangium. Purwitasari (2011) dan Purwitasari untuk jenis A. mangium di Parung Panjang Bogor. Sampai saat ini penelitian tentang persamaan alometrik yang khusus dikembangkan untuk pendugaan potensi simpanan biomassa pada A. nilotica masih terbatas. Oleh karena itu, diperlukan penelitian untuk mengetahui informasi besarnya biomassa dan karbon tegakan A. nilotica.
Penelitian ini mengukur biomassa atas permukaan yang hanya mencakup tegakan A. nilotica. Namun, tidak termasuk tunggak, akar pohon, serasah, tumbuhan bawah, dan bahan organik tanah

Berdasarkan latar belakang tersebut, maka permasalahan yang dapat dirumuskan adalah sebagai berikut :

1. Bagaimana persamaan alometrik biomassa untuk tegakan A. nilotica?

2. Berapakah potensi karbon yang tersimpan dalam tegakan A. nilotica dalam berbagai kerapatan tegakan?

Tujuan penelitian ini adalah sebagai berikut:

1. Membangun persamaan alometrik biomassa di atas permukaan tanah pohon A. nilotica

2. Menduga potensi karbon tersimpan pada tegakan A. nilotica di Taman Nasional Baluran, Situbondo, Jawa Timur.

Hasil dari penelitian ini diharapkan dapat memberikan informasi bagi Taman Nasional Baluran tentang persamaan alometrik biomassa di atas permukaan tanah dan mempermudah pendugaan biomassa di atas permukaan tanah untuk pengelolaan tegakan A. nilotica.

\section{Metode Penelitian}

\subsection{Tempat dan Waktu Penelitian}

Penelitian ini dilaksanakan di tipe hutan savanna di Taman Nasional Baluran, Kabupaten Situbondo, Propinsi Jawa Timur. Waktu penelitian dilakukan pada bulan Juni 2014.

\subsection{Bahan dan Alat}

Bahan yang digunakan adalah tegakan $A$. nilotica di Taman Nasional Baluran, Situbondo, Jawa Timur. Sedangkan Alat yang digunakan dalam penelitian ini adalah alat tulis, kompas, GPS (Global Positioning System), tally sheet, pita ukur, meteran, patok, tali rafia, golok, kantung plastik, kertas koran, timbangan $25 \mathrm{~kg}$, timbangan 1000 gram, timbangan digital, haga hypsometer, kamera digital, terpal, chainsaw, dan oven.

\subsection{Pengumpulan Data}

Jenis data yang dikumpulkan untuk penelitian ini dibagi dua, yaitu:

1. Data primer

Data primer adalah data yang diambil secara langsung dari lapangan yang meliputi bobot bagian-bagian pohon contoh (batang, cabang, ranting, daun, bunga, dan buah) dan diameter pohon A. nilotica lebih dari $5 \mathrm{~cm}$. 
2. Data sekunder

Data sekunder merupakan data penunjang penelitian berupa kondisi umum lokasi penelitian dan data lain yang diperlukan.

\subsection{Prosedur Penelitian}

\section{a. Pengambilan dan Penebangan Pohon Terpilih}

Prosedur umum untuk membuat estimasi berat dari individu masing-masing pohon yang menjadi bagian dalam pemanenan biomassa (destructive sampling) menurut BSN (2011). Pengambilan pohon contoh $A$. nilotica dilakukan di areal Resort Bama, Seksi Pengelolaan Taman Nasional Wilayah (SPTNW) I Bekol, TN Baluran, Situbondo, Jawa Timur. Pengambilan dilakukan secara destruktif dengan menebang pohon $A$. nilotica pada berbagai kelas diameter yaitu $5-10 \mathrm{~cm}, 11-20 \mathrm{~cm}$, dan $21-30 \mathrm{~cm}$. Masing-masing kelas diameter diambil tiga contoh sehingga total sembilan pohon contoh. Pohon contoh ditebang (kecuali bagian akar), dipisahkan menjadi bagian batang, cabang, ranting, daun, buah, dan bunga. Hasil contoh yang diambil akan ditimbang berat basah serta diambil dan ditimbang berat basah contoh uji yang akan dikeringkan dalam oven untuk menghasilkan berat kering tanur atau biomassa.

Untuk mengetahui diamater batang diukur diameter setinggi dada atau ketinggian 1,3 m dari pangkal pohon. Contoh uji fraksi batang cabang, ranting dan daun diambil 250 gam dengan cara memotong batang minimal seperempat keliling batang. Contoh uji bunga dan buah jika ada diambil 250 gram atau seluhnya jika berat kurang dari 250 gram.

\section{b. Analisis Vegetasi}

Kerapatan pohon dan permudaan A. nilotica sangat bervariasi mulai dari yang terendah 2 ind/ha sampai $5900 \mathrm{ind} / \mathrm{ha}$, sehingga dapat dibedakan kelas kerapatanya, kerapatan jarang $<500$ batang/ha, kerapatan sedang 500-1000 batang/ha, dan kerapatan tinggi > 1000 batang/ha (BTNB, 2013). Oleh karena itu secara umum pengambilan petak contoh dilakukan secara stratified random sampling berdasarkan kerapatan tegakan yaitu di tiga lokasi dengan tingkat kerapatan $A$. nilotica rendah, kerapatan sedang dan kerapatan tinggi. Metode yang digunakan pada pembuatan petak penelitian adalah metode petak tunggal. Menurut Soerianegara dan Indrawan (2002), ukuran petak contoh dengan luasan 0.6 ha sudah cukup mewakili. Masing-masing petak penelitian berukuran 100 x 100 m dibagi menjadi 25 subpetak berukuran 20 x $20 \mathrm{~m}$, (lihat Gambar 1). Data yang diambil berupa diameter A. nilotica yang berdiameter lebih dari $5 \mathrm{~cm}$, selanjutnya berdasarkan kelas diameter pohon, permudaan pohon $A$. nilotica dibagi menjadi pertumbuhan tingkat pancang (diameter $5-10 \mathrm{~cm}$ ), tiang (diameter 10-20 cm) dan tingkat pohon (diameter $>20 \mathrm{~cm}$ ). Oleh karena itu pada setiap petak yang berukuran $20 \mathrm{~m} \times 20 \mathrm{~m}$ dibagi lagi menjadi sub petak $5 \mathrm{~m}$ x $5 \mathrm{~m}$ untuk pengamatan pancang, $10 \mathrm{~m} \times 10 \mathrm{~m}$ untuk pengamatan tiang dan $20 \mathrm{~m} \mathrm{x} 20 \mathrm{~m}$ untuk pengamatan pohon. Data yang dikumpulkan meliputi nama jenis, diameter, tinggi total dan tinggi bebas cabang.

\subsection{Analisis Berat Kering di Laboratorium}

Contoh uji setiap fraksi pohon yang telah diambil di lapang kemudian di bawa ke laboratorium untuk diuji berat keringnya. Adapun tahapan pengujiannya yaitu dengan mengeringkan masing-masing fraksi pohon dalam oven dengan suhu $80^{\circ} \mathrm{C}$ selama 48 jam hingga mencapai berat konstan (BSN, 2011).

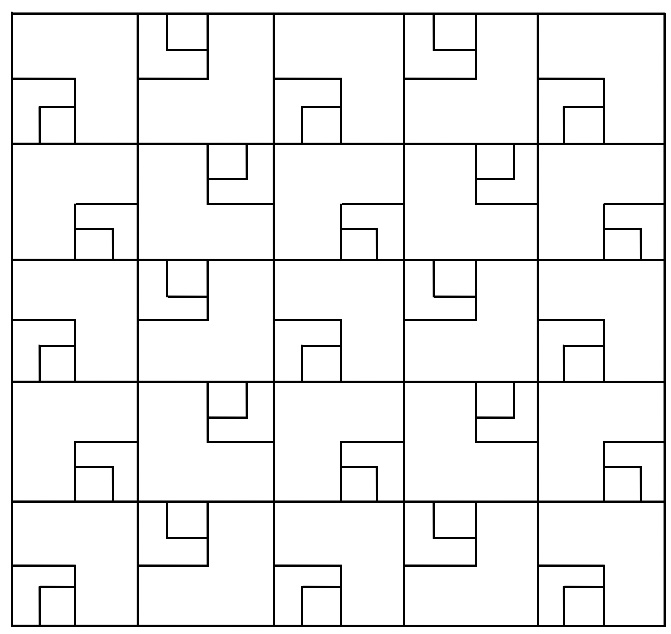

Gambar 1. Desain petak penelitian analisis vegetasi di hutan savana Taman Nasional Baluran

\subsection{Analisis Data}

1. Perhitungan berat kering total untuk penyusunan persamaan alometrik. Rumus yang digunakan untuk menghitung berat kering total menurut BSN (2011) adalah :

$$
\mathrm{Bkt}=\frac{\mathrm{Bkc} \times \mathrm{Bbt}}{\mathrm{Bbc}}
$$

Keterangan :

$$
\begin{array}{ll}
\mathrm{Bkt} & =\text { berat kering total }(\mathrm{Kg}) \\
\mathrm{Bkc} & =\text { berat kering contoh }(\mathrm{g}) \\
\mathrm{Bbt} & =\text { berat basah total }(\mathrm{kg}) \\
\mathrm{Bbc} & =\text { berat basah contoh }(\mathrm{g})
\end{array}
$$

2. Metode penyusunan persamaan alometrik

Menurut Brown (1997) berdasarkan cara memperoleh data terdapat dua pendekatan yaitu berdasarkan penggunaan dugaan volume pohon yang kemudian diubah menjadi kerapatan biomassa (ton/ha) dan pendekatan dengan menggunakan persamaan regresi biomassa atau lebih dikenal dengan persamaan alometrik. Pendekatan alometrik dengan menggunakan persamaan regresi biomassa berdasarkan diameter batang pohon. Dasar dari persamaan regresi ini adalah hanya mendekati biomassa rata-rata per pohon menurut sebaran diameter, dengan menggabungkan sejumlah pohon 
pada setiap kelas diameter dan menjumlahkan seluruh pohon untuk seluruh kelas diameter.

Biomassa di atas tanah $(\mathrm{W})=\mathrm{aD}^{\mathrm{b}}$

Keterangan :

$\mathrm{W}=$ Biomassa (berat kering per pohon) $(\mathrm{kg})$

$\mathrm{D}=$ Diameter setinggi dada $(\mathrm{cm})$

$\mathrm{a}, \mathrm{b}=$ Konstanta

Pembuatan model menggunakan program minitab 14. Data yang digunakan untuk membangun persamaan biomassa dan massa karbon total pohon dan bagian-bagian pohon (daun, ranting, cabang, batang dan akar) adalah diameter dalam centimeter dan tinggi pohon dalam meter. Model (Brown, 1997):

$$
\begin{aligned}
& \mathrm{W}=\mathrm{aD}-\mathrm{b} \\
& \mathrm{W}=\mathrm{aD} \mathrm{D}^{\mathrm{b}} \\
& \mathrm{W}=\mathrm{aD}^{2}+\mathrm{bD}-\mathrm{c}
\end{aligned}
$$

Keterangan :

$$
\begin{aligned}
& \mathrm{W}=\text { Biomassa } \\
& \mathrm{D}=\text { diameter } \\
& \mathrm{a}, \mathrm{b}, \mathrm{c}=\text { konstanta }
\end{aligned}
$$

Model pendugaan biomassa terpilih adalah $\mathrm{W}=\mathrm{aD}^{\mathrm{b}}$ karena model ini benar secara ilmiah berdasarkan pengujian statistik, praktis karena hanya menggunakan satu variabel bebas yaitu diameter saja dan lebih teliti dilakukan pengukurannya dilapangan (Widyasari et al., 2010)
3. Pendugaan potensi karbon

Potensi karbon dapat diduga melalui biomasaa tumbuhan dengan mengkonversi 0.47 dari biomassa maupun nekromassanya (BSN, 2011). Rumus yang digunakan sebagai berikut :

$$
\mathrm{C}=\mathrm{B} \times 0.47
$$

Keterangan :

$$
\begin{aligned}
\mathrm{C}= & \text { karbon }(\mathrm{kg}) \\
\mathrm{B}= & \text { biomassa tumbuhan }(\mathrm{kg}) \\
0.47= & \text { faktor konversi standar internasional } \\
& \text { untuk pendugaan karbon }
\end{aligned}
$$

\begin{tabular}{|c|c|c|c|c|c|c|c|c|}
\hline \multirow{2}{*}{$\begin{array}{l}\text { DBH } \\
(\mathrm{cm})\end{array}$} & \multicolumn{8}{|c|}{ Biomassa $(\mathrm{kg})$ tiap bagian pohon contoh } \\
\hline & batang & cabang & ranting & daun & buah & bunga & & \\
\hline 6,05 & 9,88 & 2,24 & 1,08 & 0,20 & 0,00 & & 0,00 & 13,40 \\
\hline 7,60 & 6,80 & 3,84 & 2,08 & 1,20 & 0,09 & & 0,00 & 14,01 \\
\hline 8,59 & 15,00 & 6,60 & 4,48 & 1,44 & 0,88 & & 0,01 & 28,41 \\
\hline 11,78 & 25,84 & 9,60 & 8,40 & 1,10 & 0,42 & & 0,01 & 45,37 \\
\hline 12,10 & 28,80 & 8,32 & 1,56 & 0,37 & 0,03 & & 0,00 & 39,08 \\
\hline 16,88 & 64,60 & 38,40 & 21,56 & 4,40 & 3,96 & & 0,02 & 132,94 \\
\hline 20,38 & 92,48 & 24,36 & 8,40 & 2,08 & 1,44 & & 0,02 & 128,78 \\
\hline 21,34 & 92,88 & 21,08 & 12,00 & 1,76 & 0,74 & & 0,08 & 128,54 \\
\hline 22,29 & 82,08 & 40,64 & 17,92 & 4,14 & 1,19 & & 0,07 & 146,03 \\
\hline
\end{tabular}

\section{Hasil dan Pembahasan}

\subsection{Model Alometrik Penduga Biomassa Acacia nilotica}

Bagian pohon yang digunakan untuk menentukan biomassa total tegakan A. nilotica adalah batang, cabang, ranting, daun, buah dan bunga. Data hasil perhitungan biomassa A. nilotica berdasarkan berat kering total, berat basah contoh dan berat kering contoh disajikan pada Tabel 1.

Tabel 1. Data diameter dan biomassa pohon contoh tiap bagian tanaman

Pengambilan pohon contoh masing-masing kelas diameter sebanyak tiga pohon telah sesuai dengan BSN 2011. Berdasarkan pengukuran pendahuluan pohon A. nilotica mempunyai diameter paling besar 30 $\mathrm{cm}$, sehingga dibuat 3 kelas diameter Pohon contoh yang diambil sebanyak 9 pohon karena berbagai keterbatasan tenaga dan faktor kesulitan memisahkan bagian fraksi-fraksi pohon karena pohon ini berduri dari batang sampai daun, sehingga penelitian ini merupakan penelitian pendahuluan untuk pendugaan karbon pada tegakan A. nilotica Jumlah pohon contoh 9 pohon ini hampir sama dengan penelitian Rahmat (2007) dalam Krisnawati et al. (2012) untuk A. crassicarpa di hutan tanaman di Sumatera Selatan untuk membuat persamaan alometrik sebanyak 10 pohon dan Penelitian Purwitasari (2011) pada hutan tanaman A. mangium untuk membuat allometrik penduga biomassa dan masa karbon di Parung Panjang, Bogor, sebanyak 8 pohon contoh.

Umumnya biomassa diduga secara tidak langsung menggunakan persamaan alometrik, tetapi pada penelitian ini biomassa diduga dengan metode langsung secara destruktif. Nilai biomassa didapat berdasarkan model persamaan alometrik penduga kandungan biomassa $A$. nilotica yang telah dibuat. Berdasarkan biomassa pohon contoh dapat dibuat persamaan alometrik tiap bagian pohon dan total biomassa dengan bantuan minitab dapat dilihat pada Tabel 2. 
Pada Tabel 2 dapat dilihat bahwa model alometrik untuk menduga biomassa $A$. nilotica berdasarkan nilai $\mathrm{R}^{2}$ untuk total biomassa yang dipilih adalah $\mathrm{W}=0,34$ $\mathrm{D}^{1,97}$. Hubungan antara $\mathrm{W}$ dan $\mathrm{D}$ mempunyai tingkat keterandalan yang lebih baik. Hal tersebut sejalan dengan penelitian Salim (2005) dan Limbong (2009) yang menyatakan bahwa biomassa tegakan hutan dapat diduga hanya dengan menggunakan diameter pohon. Model Tersebut sesuai dengan dengan pangkat menurut Brown (1977) yaitu $\mathrm{W}=0,118 \mathrm{D}{ }^{2,53}$ dengan $\mathrm{R}$ $=97 \%$.

Model penduga biomassa di atas permukaan tanah untuk hutan hujan tropika di Amazon bagian timur adalah $\mathrm{TAGB}=\mathrm{aDBH}^{\mathrm{b}}$ (Ducey et al., 2009), sedangkan menurut Basuki et al. (2009) untuk hutan alam di Kaliman Tengah model persamaan alometrik penduga biomassa di atas peermukaan tanah adalah $\ln (\mathrm{TAGB})=\mathrm{c}+\alpha \ln (\mathrm{DBH})$.

Tabel 2. Persamaan alometrik untuk mengukur biomassa $A$.

\begin{tabular}{|c|c|c|}
\hline Bagian & Model & $\mathrm{R}^{2}$ \\
\hline \multirow{3}{*}{ Batang } & $\mathrm{W}=0,20 \mathrm{D}^{1,99}$ & 99,2 \\
\hline & $\mathrm{W}=5,67 \mathrm{D}-48,99$ & 95,8 \\
\hline & $\mathrm{W}=0,083 \mathrm{D}^{2}+9,1 \mathrm{D}-50,80$ & 96,1 \\
\hline \multirow{3}{*}{ Cabang } & $\mathrm{W}=0,06 \mathrm{D}^{2,06}$ & 98,5 \\
\hline & $\mathrm{W}=1,99 \mathrm{D}-10,90$ & 72,6 \\
\hline & $\mathrm{W}=-0,029 \mathrm{D}^{2}+2,84 \mathrm{D}-15,98$ & 72,8 \\
\hline \multirow{3}{*}{ Ranting } & $\mathrm{W}=0,04 \mathrm{D}^{1,93}$ & 98,2 \\
\hline & $\mathrm{W}=0,88 \mathrm{D}-3,81$ & 56,2 \\
\hline & $\mathrm{W}=-0,044 \mathrm{D} 2+2,15 \mathrm{D}-11,44$ & 58,3 \\
\hline \multirow{3}{*}{ Daun } & $\mathrm{W}=0,04 \mathrm{D}^{1,36}$ & 98,7 \\
\hline & $\mathrm{W}=0,163 \mathrm{D}-0,446$ & 46,6 \\
\hline & $\mathrm{W}=-0,003 \mathrm{D}^{2}+0,25 \mathrm{D}-0985$ & 46,9 \\
\hline \multirow{3}{*}{ Buah } & $\mathrm{W}=0,002 \mathrm{D}^{2,00}$ & 98,5 \\
\hline & $\mathrm{W}=0,091 \mathrm{D}-0,315$ & 21,4 \\
\hline & $\mathrm{W}=-0,018 \mathrm{D} 2+0,60 \mathrm{D}-3,42$ & 33,9 \\
\hline \multirow{3}{*}{ Bunga } & $\mathrm{W}=0,2 \mathrm{D}^{2,00}$ & 98,4 \\
\hline & $\mathrm{W}=0,004 \mathrm{D}-0,033$ & 67,7 \\
\hline & $\mathrm{W}=0,000 \mathrm{D}^{2}-0,008 \mathrm{D}+0,041$ & 79,4 \\
\hline \multirow{3}{*}{ Total } & $\mathrm{W}=0,34 \mathrm{D}^{1,97}$ & 98,4 \\
\hline & $\mathrm{W}=8,80 \mathrm{D}-48,99$ & 93,3 \\
\hline & $\mathrm{W}=-0,01 \mathrm{D}^{2}+9,1 \mathrm{D}-50,80$ & 93,3 \\
\hline
\end{tabular}

Penduga biomassa di atas permukaan tanah jenis campuran dengan hanya memakai peubah diameter menurut Djomo et al. (2010) memberikan galat 7,4\% sedangkan dengan memakai 3 peubah (diameter, tinggi dan kerapatan kayu ) memberikan galat 3,4\%. Sedangkan menurut Brassard et al. (2011) menyatakan bahwa model hubungan $\mathrm{D}$ dengan $\mathrm{W}$ memiliki nilai $\mathrm{R}^{2}$ yang lebih tinggi daripada model hubungan D dan H dengan W.

Model perpangkatan (power) untuk menduga biomassa sesuai dengan hasil penelitian Rahmat (2007) untuk jenis A. crassicarpa di Sumatera Selatan yaitu $\mathrm{W}=0,027 \mathrm{D}^{2,891}$ dengan nilai $\mathrm{R}^{2} 0,96$ dan penelitian Heriyanto \& Siregar (2007) untuk jenis $A$. mangium di Jawa Barat yaitu $\mathrm{W}=0,199 \mathrm{D}^{2,148}$ dengan nilai $\mathrm{R}^{2}$ 0,99. Sedangkan Purwitasari (2011) untuk jenis A. mangium di BKPH Parung Panjang, Jawa Barat mendapatkan model alometrik biomassa $\mathrm{W}=$ 0,140928D 2,31 Persamaan alometrik yang dihasilkan untuk menduga biomassa hutan gambut bekas terbakar di Sumatera Selatan adalah melalui persamaan $\mathrm{W}=$ $0,153108 \mathrm{D}^{2,40}$ (Widyasari, 2010).

\subsection{Komposisi dan Struktur Tegakan A. nilotica}

Hasil pengukuran kerapatan dan luas bidang dasar tersaji pada Tabel 3. Berdasarkan Tabel 3, kerapatan pohon pada tegakan $A$. nilotica termasuk tipe hutan normal yang menunjukkan hubungan antara diameter dan jumlah pohon mempunyai kurva $\mathrm{J}$ terbalik, yaitu semakin tinggi diameter semakin turun jumlah pohonnya terutama pada tegakan A. nilotica pada kerapatan tinggi. Hal ini sesuai hasil penelitian Sumadi \& Siahaan (2011) pada diameter $4 \mathrm{~cm}$ jumlah pohon (N/ha) sebanyak 1136 sedangkan pada diameter $40 \mathrm{~cm}$ sebanyak 167 . Hal ini diperkuat dengan hasil penelitian Bismark et al. (2008), bahwa semakin besar kelas diameter pohon maka populasi pohon akan semakin sedikit. Tegakan A. nilotica rapat memiliki kerapatan tegakan dan luas bidang dasar yang lebih tinggi karena memiliki jumlah pohon lebih banyak dibandingkan tegakan lain. Total luas bidang dasar (Lbds) di hutan gambut merang bekas terbakar adalah sebesar $14,71 \mathrm{~m}^{2} /$ ha dan mengalami penurunan akibat kebakaran hutan sebesar 40,23\% (Widyasari, 2010) dan rata-rata total Lbds pada berbagai kedalaman gambut di hutan gambut primer yaitu $24,61 \mathrm{~m}^{2} /$ ha (Istomo, 2006). Menurut Finer et al. (2010) faktor lingkungan dan faktor tegakan belum bisa menjelaskan adanya variasi secara nyata dalam menduga biomassa kecuali luas bidang dasar (lbds) pohon.

Tabel 3. Hasil pengukuran kerapatan tegakan dan luas bidang dasar

\begin{tabular}{ccc}
\hline Tegakan & $\begin{array}{c}\text { Jumlah Pohon } \\
\text { (ind/ha) }\end{array}$ & LBDS $\left(\mathrm{m}^{2} / \mathrm{ha}\right)$ \\
\hline Tinggi & 1405 & 10.58 \\
Sedang & 976 & 6.41 \\
Jarang & 159 & 4.33 \\
\hline
\end{tabular}

Hasil pengukuran jumlah pohon dalam berbagai kelas diameter tersaji pada Tabel 4. Tabel 4 dapat dilihat bahwa kerapatan tegakan tinggi didominasi oleh pohon berdiameter $5-15 \mathrm{~cm}$, tegakan sedang juga banyak ditemukan pohon berdiameter berkisar 5-25 $\mathrm{cm}$, sedangkan tegakan jarang lebih didominasi oleh pohon berdiameter lebih dari $20 \mathrm{~cm}$. Variasi diameter ini dipengaruhi oleh kerapatan tegakan karena semakin rapat tegakan, diameter pohon rata-rata lebih kecil dibandingkan diameter rata-rata pada tegakan yang lebih jarang (Maretnowati, 2004).

Tabel 4. Hasil pengukuran jumlah pohon dalam berbagai kelas diameter

\begin{tabular}{lcccccc}
\hline & \multicolumn{7}{c}{ Kelas diameter } \\
\cline { 2 - 7 } Kerapatan & $5-10$ & $10-15$ & $15-20$ & $20-25$ & $25-30$ & $>30$ \\
Tegakan & $\mathrm{cm}$ & $\mathrm{cm}$ & $\mathrm{cm}$ & $\mathrm{cm}$ & $\mathrm{cm}$ & $\mathrm{cm}$ \\
\hline Tinggi & 64 & 94 & 0 & 1 & 0 & 0 \\
Sedang & 22 & 70 & 14 & 3 & 0 & 1 \\
Jarang & 1 & 13 & 13 & 20 & 12 & 8 \\
\hline
\end{tabular}




\subsection{Potensi Simpanan Karbon Berdasarkan Biomassa Tegakan Acacia nilotica}

Hasil pendugaan total kandungan biomassa dan karbon pada setiap kerapatan tersaji pada Tabel 5 . Pada Tabel 5 dapat dilihat bahwa biomassa tegakan $A$. nilotica semakin meningkat dengan meningkatnya kerapatan tegakan, demikian pula potensi karbon semakin meningkat dengan meningkatnya kerapatan tegakan. Rata-rata biomassa A. nilotica sebesar 25,36 ton/ha dan potensi karbon sebesar 11,92 ton/ha. Biomassa tegakan dipengaruhi oleh umur tegakan, sejarah perkembangan vegetasi, komposisi dan struktur tegakan serta faktor iklim seperti curah hujan (Kusmana, 1993). Kelas diameter pada kerapatan pohon juga mempengaruhi kandungan biomassa yang tersimpan, semakin besar diameter suatu pohon maka $\mathrm{CO}_{2}$ yang diserapnya semakin besar (Dharmawan \&
Siregar, 2008). Potensi simpanan biomassa pada akhirnya akan mempengaruhi simpanan karbon pada masing-masing tegakan.

Karbon merupakan salah satu unsur yang mengalami daur dalam ekosistem. Tanaman menyerap $\mathrm{CO}_{2}$ dari atmosfer kemudian menyimpannya dalam bentuk biomassa tumbuhan dan melepaskan gas $\mathrm{O}_{2} \mathrm{ke}$ atmosfer melalui proses fotosintesis. Hutan yang sedang tumbuh atau masih muda akan berfungsi sangat baik sebagai carbon stock, karena vegetasinya secara cepat menyerap gas $\mathrm{CO}_{2}$ pada proses fotosintesis dalam rangka tumbuh dan berkembangnya vegetasi. Pohon-pohon muda tumbuh lebih cepat dan menyerap lebih banyak $\mathrm{CO}_{2}$ daripada pohon-pohon tua. Pohon-pohon tua paling sedikit mengikat $\mathrm{CO}_{2}$, tetapi lebih banyak menyimpan karbon dalam biomassanya (Retnowati, 1998).

Tabel 5. Simpanan biomassa dan karbon pada tegakan A. nilotica pada berbagai tingkat pertumbuhan

\begin{tabular}{|c|c|c|c|c|c|c|c|c|}
\hline \multirow{3}{*}{ KT } & \multicolumn{8}{|c|}{ Potensi Biomassa (B) dan Karbon (K) ton/ha } \\
\hline & \multicolumn{2}{|c|}{ Pancang } & \multicolumn{2}{|c|}{ Tiang } & \multicolumn{2}{|c|}{ Pohon } & \multicolumn{2}{|c|}{ Total } \\
\hline & $\mathrm{B}$ & $\mathrm{K}$ & $\mathrm{B}$ & $\mathrm{K}$ & $\mathrm{B}$ & $\mathrm{K}$ & $\mathrm{B}$ & $\mathrm{K}$ \\
\hline $\mathrm{T}$ & 16,53 & 7,77 & 17,71 & 8,32 & 0,14 & 0,07 & 34,38 & 16,16 \\
\hline $\mathrm{S}$ & 5,29 & 2,48 & 18,06 & 8,49 & 0,75 & 0,35 & 24,10 & 11,33 \\
\hline $\mathrm{J}$ & 0,51 & 0,24 & 7,85 & 3,69 & 9,23 & 4,34 & 17,59 & 8,27 \\
\hline $\mathrm{R}$ & 7,44 & 3,50 & 14,54 & 6,83 & 3,37 & 1,59 & 25,36 & 11,92 \\
\hline
\end{tabular}

Keterangan :

$\mathrm{KT}=$ Kerapatan tegakan

$\mathrm{T}=$ Tinggi

$\mathrm{S}=$ Sedang

$\mathrm{J}=$ Jarang

Penambahan jumlah biomassa akan diikuti oleh penambahan jumlah potensi simpanan karbon. Hal ini menunjukkan bahwa karbon dan biomassa memiliki korelasi yang positif sehingga jika ada peningkatan atau penurunan biomassa maka akan menyebabkan peningkatan atau penurunan karbon.

Maretnowati (2004), simpanan karbon yang terkandung dalam tegakan berhubungan erat dengan pertumbuhan tegakan, simpanan karbon cenderung terus meningkat sampai pertumbuhan tegakan mencapai optimal kemudian relatif stabil. Besarnya potensi karbon yang dikonversi dari biomassa sangat dipengaruhi oleh besarnya diameter pohon. Kerapatan tegakan dan jumlah pohon juga faktor yang menentukan simpanan karbon pada areal tersebut, selain itu kerapatan tegakan mengindikasikan kualitas tempat tumbuh (Ridwanullah, 2011).

Hasil simpanan karbon pada penelitian ini tidak jauh berbeda dengan hasil penelitian Mungkomdin (1993) besar simpanan karbon A. nilotica rata-rata 17 ton/ha pada tempat tumbuh sedang dan hanya menyerap sebesar 12 ton/ha pada tempat tumbuh terdegradasi. Jika dibandingkan dengan potensi simpanan karbon jenis akasia lainnya, potensi simpanan karbon ini lebih kecil dari A. mearnesii yang menunjukkan potensial karbon tertinggi 78 ton/ha dalam rotasi 10 tahun, sedangkan $A$. mangium sebesar
25,42 ton/ha di BKPH Parung Panjang, KPH Bogor, Perum Perhutani Unit III Jawa Barat dan Banten (Purwitasari, 2011).

Tipe vegetasi A. nilotica di Taman Nasional Baluran memang tergolong pada tipe savana yaitu padang rumput yang ditumbuhi pohon-pohon kecil atau semak dengan kerapatan umumnya tergolong jarang. Tipe vegetasi tersebut berbeda dengan tipetipe hutan lahan kering, hutan gambut, hutan kering pegunungan (montana) yang mempunyai simpanan karbon yang lebih besar. Suwarna et al. (2012) memperoleh simpanan karbon di hutan rawa gambut di Riau untuk pohon dan permudaan di hutan primer 133,43 ton/ha, hutan bekas tebangan 97,19 ton/ha hutan sekunder 86,43 ton/ha hutan terdegradasi 2,96 ton/ha. Ludang \& Jaya (2007) memperolah data simpanan karbon di hutan gambut primer di Kalimantan Tengah untuk pohon dan permudaan 351,33 ton karbon/ha dan di hutan gambut bekas tebangan 173,33 ton/ha. Lasco et al. (2006) pada hutan lahan kering primer Dipterokarpa Filipina memperoleh 190 ton karbon/ha dan pada hutan lahan kering bekas tebangan 1-5 tahun 91,00 ton karbon/ha sedangkan Cuesta et al. (2011) pada hutan kering pegunungan primer di Peru memperoleh 69,20 ton karbon/ha dan pada hutan lahan kering pegunungan bekas terbakar 45,50 ton karbon/ha. 
Hasil penelitian pada tegakan A. mangium meperlihatkan bahwa terdapat perbedaan kadar karbon pada bagian-bagian pohon (akar, batang utama, cabang, ranting dan daun). Massa karbon terbesar terdapat pada bagian batang utama dan yang terkecil terdapat pada bagian daun. Model alometrik untuk biomassa pohon $A$. mangium dan model alometrik massa karbon pohon $A$. mangium adalah $\mathrm{C}$ $=0,060255 \mathrm{D}^{2,39}$. Potensi karbon pohon $A$. mangium di BKPH Parung Panjang sebesar 25,41 ton/ha. (Purwitasari, 2011)

Adanya perbedaan simpanan karbon disebabkan oleh kerapatan tegakan, umur tegakan, kualitas tempat tumbuh, iklim, topografi, karakteristik tanah, komposisi umur pohon, dan perlakuan silvikultur yang diberikan (Balitbang, 2010). A. nilotica merupakan spesies invasif yang mengganggu ekosistem savanna di TN Baluran, sehingga sering dilakukan pemusnahan $A$. nilotica secara mekanis maupun kimiawi. Perbedaan simpanan karbon pada setiap tegakan juga dipengaruhi oleh kerapatan tumbuhan, jumlah pohon, dan rata-rata diameter pohon. Semakin besar sebaran diameter pohon, kandungan biomassa pada pohon tersebut juga semakin bertambah.

A. nilotica merupakan salah satu species invasif di savana Taman Nasional Baluran karena telah merubah komposisi penyusun savana. Kegiatan pemberantasan secara kimiawi kurang efektif dan efisien dan membutuhkan biaya yang besar. Pemberantasan secara mekanis dengan penebangan belum berhasil optimal (Djufri, 2006).

Untuk menekan laju penyebaran akasia berduri, bisa dilakukan dengan cara memanfaatkan spesies tumbuhan tersebut agar menjadi barang yang berguna. Proses pemanfaatannya bisa dilakukan dengan melibatkan masyarakat atau pihak terkait. Jenis pemanfaatannya seperti pengambilan polong dan biji akasia berduri untuk dijadikan bahan campuran makanan; pengambilan daun untuk pakan ternak; kulit kayu dimanfaatkan sebagai sumber tannin untuk herbisida; pengambilan batang untuk kayu bakar atau arang beriket; dan lain-lain (Hermawan, 2012). Oleh karena itu dalam kaitannya dengan pengelolaan jenis invasif species $A$. nilotica diperlukan zonasi untuk pengendalian $A$. nilotica berdasarkan tingkat kerapatan tegakan. Pada zona kerapatan tegakan jarang dan sedang ( $<1000$ pohon/ha) A. nilotica harus ditebang habis yang dijadikan areal savana yang bebas dari A. nilotica, sedangkan pada tegakan rapat (> 1000 pohon/ha) yang didominasi $A$. nilotica muda tetap dipertahankan sebagai tegakan A. nilotica yang masih mempunyai fungsi menyerap karbon tinggi dan dapat dimanfaatkan untuk masyarakat.

\section{Kesimpulan}

1. Model penduga kandungan biomassa pohon $A$. nilotica yang terpilih adalah model $\mathrm{W}=0,34 \mathrm{D}^{1.96}$

2. Potensi simpanan karbon total tegakan A. nilotica tinggi sebesar 16,16 ton/ha, tegakan sedang 11,33 ton/ha, dan tegakan jarang 8,27 ton/ha dengan rata rata sebesar 11,92 ton/ha.

3. Jika dilihat dari potensi simpanan karbonnya yang cukup tinggi, perlu adanya upaya konservasi pada tegakan dengan kerapatan tinggi. Karena pada tegakan tersebut didominasi oleh pohon A. nilotica muda sehingga simpanan karbonnya akan terus meningkat seiring pertumbuhan tegakannya.

\section{Daftar Pustaka}

[1] [Balitbang] Badan Penelitian dan Pengembangan kehutanan. 2010. Cadangan karbon pada berbagai tipe hutan Indonesia, Balitbang, Jakarta.

[2] [BSN] Badan Standardisasi Nasional, 2011. Pengukuran dan penghitungan cadangan karbon-Pengukuran lapangan untuk penaksiran cadangan karbon hutan (ground based forest carbon accounting). BSN, Jakarta.

[3] [BTNB] Balai Taman Nasional Baluran, 1999. Rancangan Pencabutan Seedling/Anakan Hasil Pembongkaran secara Mekanis 150 Ha di Savana Bekol. Taman Nasional Baluran, Reboisasi Taman Nasional Baluran, Banyuwangi.

[4] [BTNB] Balai Taman Nasional Baluran, 2013. Sebaran invasi Acacia nilotica di Taman Nasional Baluran. Taman Nasional Baluran, Situbondo.

[5] Basuki, T. M., P. E. Laakea, A. K. Skidmorea, Y. A. Hussina, 2009. Allometric equations for estimating the above-ground biomass in tropical lowland and Dipterocarp forests. Journal of Forest Ecology and Management. 257(8), pp. 1684-1694.

[6] Bismark, M., N. M. Heriyanto, S. Iskandar, 2008. Biomassa dan kandungan karbon pada hutan produksi di Cagar Biosfer Pulau Siberut, Sumatera Barat. Jurnal Penelitian Hutan dan Konservasi Alam. 5(5), pp. 397-407.

[7] Brassard, B. W., H. Y. H. Chen, Y. Bergeron, D. Pare, 2011. Coarse root biomass allometric equations for Abies balsamea, Picea mariana, Pinus banksiana, and Populus tremuloides in the boreal forest of Ontario, Canada. Journal of Biomass and Bioenergy,35, pp. 4189-4196.

[8] Brenan J. P. M., 1983 Manual on taxonomy of Acacia species: present taxonomy of four species of Acacia ( $A$. albida, A. senegal, A. nilotica, A. tortilis). FAO, Rome. pp. 20-24.

[9] Brown, S. 1997. Estimating Biomass and Biomass Change of Tropical Forest A Primer. USA: FAO. Forestry Paper.134, pp. 10-13.

[10] Cuesta, R. M. R. et al., 2011. Implication of fires on carbon budgets in Andean cloud montane forest : the importance of peat soils and tree reprouting. Jaournal of Forest Ecology and Management. 186:125-132.

[11] De Salis S. M., M. A. Assis, P. Mattos, A. C. S. Piao, 2006. Estimating the aboveground biomass and wood volume of savanna woodlands in Brazil's Pantanal wetlands based on allometric correlations. Forest Ecology and Management. 228(1-3): 61-68.

[12] Dharmawan, I.W.S., C.A. Siregar, 2008. Karbon tanah dan pendugaan karbon tegakan Avicennia marina (Forsk.) Vierh. di Ciasem Purwakarta. Jurnal Penelitian Hutan dan Alam. 4(1):317-326.

[13] Djomo A. N., A. Ibrahim, J. Saborowski, G. Gravenhorst, 2010. Allometric equations for biomass estimations in Cameroon and pan moist tropical equations including biomass data from Africa. Journal of Forest Ecology and Management. 186, pp. 125-132.

[14] Djufri, 2006. Studi autekologi dan pengaruh invasi akasia (Acacia nilotica) (L.) Willd. Ex. Del. Terhadap eksistensi savana dan strategi penanganannya di Taman Nasional Baluran Banyuwangi Jawa Timur [disertasi]. Institut Pertanian Bogor, Bogor.

[15] Ducey M. J., D. J. Zarin, S. S. Vasconcelos, M. M. Araujo, 2009. Biomass equations for forest regrowth in the Eastern 
Amazon using randomized branch sampling. Journal of Acta Amazonica. 39(2), pp. 349-360.

[16] Finer, L., M. Ohashi, K. Noguchi, Y. Hirano, 2010. Factors causing variations in fine root biomass in forest ecosystem. Journal of Forest Ecology and Management. 261, pp. 265277.

[17] Heriyanto, N. M., C. A. Siregar. 2007. Biomasa dan kandungan karbon pada hutan tanaman tusam (Pinus merkusii Jungh et de Vriese) umur lima tahun di Cianten Bogor. Jurnal Penelitian Hutan dan Konservasi Alam. 4(1): 75-81.

[18] Hermawan, R., C. Wulan, J. P. Siregar, A. Agustina, 2012. Manajemen spesies invasif akasia berduri (Acacia nilotica (1.) willd. ex. del) di Taman Nasional Baluran, Banyuwangi, Jawa Timur.

https://rudihermawanoke.wordpress.com/2012/09/27/manaj emen-spesies-invasif-akasia-berduri-acacia-nilotica-1-willdex-del.

[19] Istomo, 2006. Kandungan fosfor dam kalsium pada tanah dan biomassa hutan rawa gambut (Studi kasus di wilayah HPH PT. Diamond Raya Timber, bagan Siapi-api, Provinsi Riau. Jurnal Manajemen Hutan Tropika. 12(3), pp. 40-57.

[20] Jenkins, C.J., D.C. Chojnacky, L.S. Heath, R.A. Birdsey, 2003. National-scale Biomass Estimators for United States Tree Species. Forest Science. 49 (1), pp. 12 -30.

[21] Kusmana, C., 1993. A study on mangrove forest management base on ecological data in East Sumatra, Indonesia [Disertasi]. Kyoto University, Faculty of Agricultural, Japan.

[22] Lasco, R.D. et al., 2006. Carbon stocks assessment of a selectively logged Dipterocarp forest and wood processing mill in the Philippines. Journal of Tropical Forest Science. 18 (4), pp. 166-172.

[23] Limbong, H.D.H., 2009. Potensi karbon pada lahan gambut bekas terbakar (Studi kasus di IUPHHK PT. SBA Wood Industries, Sumatera Selatan) [Tesis \} Program Pascasarjana Institut Pertanian Bogor.

[24] Ludang, Y., H.P. Jaya, 2007. Biomass and carbon content in tropical forest of Central Kalimantan. Journal of Applied Scince in Environmental Sanitation. 2 (1), 7-12.

[25] Maretnowati, N.A., 2004. Pengukuran potensi cadangan karbon di lahan agroforestri di Desa Cileuya, Perum Perhutani Unit II Jawa barat, KPH Kuningan, BKPH Cibingbin, RPH Cileuya dan BKPH Luragung, RPH Sukasari [skripsi]. Institut Pertanian Bogor, Bogor.

[26] Mungkodiman, S., 1981. Forests as a source of food to Rural Communities in Thailand. FAO, NO. RAPA 52, Bangkok.

[27] Navar, J., 2009. Allometric equations for tree species and carbon stocks for forest northwestern Mexico. Journal of Forest Ecology and Management. 257, pp. 427-434.

[28] Purwitasari, H. 2011. Model persamaan alometrik biomassa dan massa karbon pohon Akasia Mangium (Acacia mangium Willd.) [skripsi]. Institut Pertanian Bogor, Bogor.

[29] Rahmat, M., 2007. Pendugaan serapan karbon hutan tanaman Acacia crassicarpa pada lahan gambut. Laporan Hasil Penelitian BPK Palembang, Palembang.

[30] Retnowati, 1998. Kontribusi hutan tanaman Eucaliptus grandis Maiden sebagai rosot karbon di Tapanuli Utara. Buletin Penelitian Hutan 11. Pusat Penelitian dan Pengembangan Hutan dan Konservasi Alam. Bogor.

[31] Ridwanullah, D., 2011. Pendugaan fluktuasi kandungan karbon melalui analisis biomassa pohon Akasia (Acacia mangium Willd) studi kasus PT. Sumatra Sylva Lestari [tesis]. Universitas Riau, Riau.

[32] Salim, 2005. Profil kandungan karbon pada tegakan puspa (Schima wallichii Korth) [Tesis] Program Pascasarjana, Institut Pertanian Bogor, Bogor.

[33] Salis S. M., M. A. Assis, P. P. Mattos, A. C. S. Pia o, 2006 Estimating the aboveground biomass and wood volume of savanna woodlands in Brazil's Pantanal wetlands based on allometric correlations. Forest Ecology and Management. 22(2006), pp. 61-68.

[34] Smith, E.J., L.S. Heath, P.B. Woodbury, 2004. How to estimate forest carbon for large area from inventory data. Journal of Forestry July/August.

[35] Soerianegara, I., A. Indrawan, 2002. Ekologi Hutan Indonesia. Fakultas Kehutanan, Institut Pertanian Bogor, Bogor.

[36] Sumadi, A. H. Siahaan., 2011. Pengaturan kerapatan tegakan bambang berdasarkan hubungan antara diameter batang dan tajuk. Jurnal Penelitian Hutan Tanaman. 8(5), $259-265$.

[37] Sutaryo D., 2009. Perhitungan Biomassa Sebuah Pengantar untuk Studi Karbon dan Perdagangan Karbon. Wetlands Internasional Indonesia Programme, Bogor.

[38] Suwarna, U., Elias, D. Darusman, Istomo., 2012. Estimasi simpanan karbon total dalam tanah dan vegetasi di hutan gambut tropika di Indonesia. Jurnal Manajemen hutan Tropika. 18(2), pp. 118-128.

[39] Tresnawan, H., U. Rosalina, 2002. Pendugaan biomassa di atas tanah di ekosistem hutan primer dan hutan bekas tebangan (studi kasus Hutan Dusun Aro, Jambi). Jurnal Manajemen Hutan Tropika. 7(1), pp. 15-29.

[40] Wardhana, H.F.P, 2011. Pendugaan potensi simpanan karbon pada tegakan pinus (Pinus merkusii Jungh. Et de Vriese) di KPH Cianjur, Perum Perhutani Unit III Jawa Barat dan Banten [skripsi]. Institut Pertanian Bogor, Bogor.

[41] Wicaksono, D., 2004. Penaksiran potensi biomassa pada hutan tanaman mangium (Acacia mangium Willd.) (Kasus hutan tanaman PT. Musi Hutan Persada, Sumatera Selatan) [Skripsi]. Institut Pertanian Bogor, Bogor.

[42] Widyasari, N.A.E, B.H. Saharjo, Solichin, Istomo, 2010. Pendugaan biomassa dan potensi karbon terikat di atas permukaan tanah hutan rawa gambut bekas terbakar di Sumatera selatan. Jurnal Ilmu Pertanian Indonesia. 15 (1), pp. 41-49.

[43] Widyasari, N.A.E., 2010 Pendugaan biomassa dan potensi karbon terikat di atas permukaan tanah pada hutan gambut merang bekas terbakar di Sumatera Selatan [Tesis]. Institut Pertanian Bogor, Bogor. 